\title{
Forest Biomass, Carbon Stocks, and Macrofungal Dynamics: A Case Study in Costa Rica
}

\author{
Carlos Rojas $^{1,2}$ and Erick Calvo ${ }^{1}$ \\ ${ }^{1}$ Engineering Research Institute, University of Costa Rica, 11501 San Pedro de Montes de Oca, Costa Rica \\ ${ }^{2}$ Department of Biosystems Engineering, University of Costa Rica, 11501 San Pedro de Montes de Oca, Costa Rica \\ Correspondence should be addressed to Carlos Rojas; rojas_carlos@outlook.com
}

Received 18 December 2013; Revised 17 February 2014; Accepted 17 February 2014; Published 20 March 2014

Academic Editor: Piermaria Corona

Copyright (c) 2014 C. Rojas and E. Calvo. This is an open access article distributed under the Creative Commons Attribution License, which permits unrestricted use, distribution, and reproduction in any medium, provided the original work is properly cited.

There are few published studies providing information about macrofungal biology in a context of forest dynamics in tropical areas. For this study, a characterization of above-ground standing tree biomass and carbon stocks was performed for four different forest subtypes within two life zones in Costa Rica. Fungal productivity and reproductive success were estimated and analyzed in the context of the forest systems studied and results showed fungal dynamics to be a complex and challenging topic. In the present study, fungal productivity was higher in forest patches with more tree density but independent from life zones, whereas fungal biomass was higher in premontane areas with ectomycorrhizal dominant trees. Even though some observed patterns could be explained in terms of climatic differences and biotic relationships, the high fungal productivity observed in dry forests was an interesting finding and represents a topic for further studies.

\section{Introduction}

Macroscopic fungi within the group of the Basidiomycota stand out among human groups for their aesthetic beauty and role in sociocultural paradigms [1]. Ironically, the fungi are one of the biological groups for which limited scientific data in relation to ecosystem dynamics are available (e.g., [2]), and thus popular beliefs are dramatically based on speculation. In fact, the fungi comprise one of the groups for which fine information on natural history, ecological strategies, and across-level trophic relationships still accumulates at a slow pace (see [3]). An obvious constraint of the situation is that the study of modern evolutionary questions of forest functioning, particularly in tropical areas with high levels of nutrient recycling, develops at an even slower speed.

The paradox of the research on the tree-fungus system in the tropics derives from the fact that even though it is an important component of forest dynamics, there are a comparatively small number of local scientists generating data about the different shapes of the relationship. In the past, some interactions such as saprophytism, parasitism, endophytism, lichenization, and mycorrhization have been used to generate functional data on tropical fungi (e.g., [4]). However, an integration with forest ecology research is weak, and thus the information generated has been useful for tropical fungal biologists but not necessarily for forest ecologists. For instance, in the case of mycorrhizal research, most of the efforts on tropical areas have focused on the applied aspects of the fungus-plant relationship (e.g., agriculture; see [5]).

This bias has created an information gap between what is known about the species participating in the relationship and their ecosystem role as a biological unit. Such disparity is evident in comparative functional studies between natural versus managed forest systems since usually different approaches are taken to study either one. The problem of this strategy is that the low number of comparative studies on natural systems also translates into a weak database of scientific parameters for the evaluation of forest performance in managed scenarios (see [4]). In the context of ecosystem restoration and conservation of genetic biodiversity, this is a critical point that needs to be stressed by researchers involved in the decision-making process. 
The case of Costa Rica is not different to the situation in most developing tropical countries. Biological research in this area has focused on the generation of baseline data at the species level and has not been traditionally integrated with functional dynamics research. Ironically, during recent years the National Biodiversity Institute has estimated that after the insects, fungal species are the dominant forms in the country with about $13 \%$ of the total potential biodiversity [6]. However, such a level of biological prominence and potential importance in forest dynamics does not match the development of integrated research lines since only a handful of local researchers generate information about the topic. Even though the situation is not as precarious as in other countries in Central America where the majority of functional relationships have not even been studied, it does reflect the need to generate regional information on the role of interactive biological units in forest dynamics research.

Within this framework of limited data about functional relationships in tropical areas, a weak research focus on the tree-fungus relationship in Costa Rica and a local trend to generate valuable data on forest dynamics is that the present study has been designed. As such, the primary objective of the study presented herein is to generate baseline data about the dynamics of the tree-fungus relationship in contrasting local environments as a model to study forest management practices and their effect on species and functional diversity.

\section{Material and Methods}

This study was carried out between 2011 and 2013 in Costa Rica. The areas selected were the Grecia Forest Reserve (hereafter referred to as Grecia) and the Horizontes Experimental Forest Station (referred to as Horizontes). The first area is located in a premontane wet forest zone with a mean temperature around $17^{\circ} \mathrm{C}$, a precipitation close to $3500 \mathrm{~mm}$ rain/year, and a mean elevation of $1700 \mathrm{~m}$ above sea level. The second area is located within the lowland dry forest zone with a mean temperature around $26^{\circ} \mathrm{C}$, a precipitation close to $1300 \mathrm{~mm}$ rain/year, and a mean elevation of $155 \mathrm{~m}$ above sea level.

The Grecia Forest Reserve is a 2000-hectare area created with the purpose of protecting water resources and comprised by a mixture of public and private lands. In a 30hectare public section called Bosque del Niño, there is a 8hectare forest patch reforested in 1979 with the introduced Cupressus lusitanica. The rest of that patch is comprised by a native Quercus-dominated forest.

In contrast, the Horizontes Experimental Forest Station is a 7000-hectare public area created in 1989 with the purpose of studying the process of reforestation and ecosystem restoration in the dry forest life zone of Costa Rica. In Horizontes, a 53-hectare section of pasture was planted with a combination of native trees in 1991 and it is today an experimental forest patch used by a series of researchers.

2.1. Study Plots. In each of the study areas, two subareas representing different forest types were selected and a series of two $20 \times 50 \mathrm{~m}$ plots was established in them for a total of eight plots for the complete study. In Grecia, the two subareas selected were the Cupressus lusitanica patch (abbreviated hereafter as G1) and the Quercus-dominated section (G2). In Horizontes, the two subareas were the Samanea samanHymenaea courbaril (abbreviated as H1) and the Hymenaea courbaril-Diphysa americana $(\mathrm{H} 2)$ reforestation treatments.

The study plots were georeferenced with a Garmin Nüvi 40, marked with flagging tape, and visited during the dry and wet seasons of 2012 and 2013. A HOBO U12-012 datalogger positioned in the middle of each of the eight plots recorded the temperature (abbreviated as T), atmospheric moisture (AM), and illuminance (I) for those two years. Datasets from replicated treatments were combined and averaged to obtain mean values and standard deviations.

2.2. Protocol for Tree Data. In all study plots, diameter at breast height (abbreviated hereafter as DBH) was calculated by using field collected information with a Stanley 34-794 field measuring tape. Canopy height $(\mathrm{CH})$ was calculated by measuring the horizontal distance between an arbitrary point and the tree under study as well as the angle between such horizontal and an imaginary line to the tree crown with a Leica Disto D5 Laser Range Finder. A trigonometric calculation provided the height value after corrections for terrain slope and distance between the ground and the horizontal. Tree volume (TV) was calculated assuming a tubular shape of the tree trunk and the values for $\mathrm{DBH}$ and tree height obtained in previous steps.

An estimation of the above ground biomass (AGB) was performed using the data for living standing trees. For this calculation, the following adjusted equation from Chou and Gutiérrez-Espeleta [7] for Costa Rican tropical forest was used:

$$
B^{2 / 5}=0.1438+0.2051 \cdot \mathrm{dbh} \cdot \delta-0.0744(\mathrm{dap}-50) x .
$$

In this equation $B$ is the biomass in $\mathrm{kg}$, $\mathrm{dbh}$ is the diameter at breast height in $\mathrm{cm}, \delta$ is the wood density in $\mathrm{g} / \mathrm{cm}^{3}$, dap is diameter at breast height, and $x$ is a dichotomic variable that equals 1 when $\mathrm{dbh} \geq 50 \mathrm{~cm}$ and 0 when $\mathrm{dbh}<50 \mathrm{~cm}$. In all cases, the wood density values used were the recommended ones by the IPCC [8] for the forest types evaluated in the present study.

In a similar way, a value of 0.49 for the carbon fraction of aboveground forest biomass was used for the calculation of above ground carbon (AGC) from biomass according to the recommendation of the IPCC. For the calculation of $\mathrm{CO}_{2}$ equivalent sequestered unit $\left(\mathrm{CO}_{2}-\mathrm{EU}\right)$, the values of carbon per tree were multiplied by a factor equal to 3.667 , based on the molecular weight ratio of carbon dioxide to molecular carbon. The recommended values from the IPCC [8] were also used to calculate the below ground biomass (BGB) in the study plots by using the below to above ground biomass ratios known for tropical mountain [9] and tropical dry forests [10] in the case of Grecia and Horizontes, respectively.

2.3. Protocol for Fungal Data. In the case of all forest subtypes, several planned visits during the rainy season were carried 
out in order to collect fungal fruiting bodies. For the purpose of this project, only macroscopic (larger than $1 \mathrm{~cm}$ ) fungi belonging to the basidiomycete group were considered. In all study plots, collections were carried out by two people and fruiting bodies were collected up to $50 \mathrm{~cm}$ of vertical distance from the ground.

Once collected, all fruiting bodies were carefully taken to a field station where all morphospecies were separated, identified to the genus level, and assigned to either the saprophyte or the mycorrhizal functional category. Each fruiting body was then studied separately and both the pileus (gill supporting structure at the apex of stalk) and stalk diameter were measured using a Starret 799 digital caliper. With both measurements, an estimation of the hymenial surface (area where spores are produced) was performed by calculating the result of the pileus area minus the stalk area. For these calculations, it was assumed that the shape of both the pileus and the stalk was circular as it is the case for the majority of umbrella shaped fungi. In the case of flat wood decaying fungi, the hymenial area was calculated by assuming rectangular shapes.

The weight of each fruiting body was also measured in the field with an A\&D N29 digital scale and this measurement was considered as the wet weight value. For the calculation of fungal biomass, dry weights were calculated indirectly by estimating that about $21 \% \pm 4 \%$ of the wet weight values in the forest types studied was due to biomass. Even though the relationship between wet/dry weight is species-specific, a general value was used as a proxy for the fungal communities studied due to the lack of enough information for some genera and the homogeneity of values observed during the analysis.

The latter percentage was obtained after measuring and analyzing the wet to dry weight relationship of a 500 fruiting body random sample from both study areas that took place in areas adjacent but outside of the study plots. Dry weights were considered the value for biomass after a correlation analysis showed a high level of consistency in the water loss relationship at the mentioned percentage value $(\rho=0.81)$. In this case, both weight measurements were performed in the field and the measurement of dry weights took place after a $24 \mathrm{~h}$ period in which the fruiting bodies were dried out in a Thermolyne DV35435 oven at $60^{\circ} \mathrm{C}$.

With the values for hymenial surface and biomass, the ratio between these parameters was calculated in order to correct the error inherent to one-dimensional biometric measurements. The latter ratio, herein referred to as reproductive success ratio, was used to analyze the tree-fungus relationship in the forest types studied since it provides an indication of the resources used in the formation of true reproductive organization (hymenium) in relation to the formation of reproductive assisting structures (fruiting body itself). Such ratio is the equivalent to the "evolutionary effectiveness" value mentioned by [11], but in this study it was preferred to use the term reproductive success ratio.

2.4. Analysis. For all basic and relational analyses using tree and fungal data, the statistical software JMP, version 10 (SAS Institute 2012), was used. In all cases, data normality was evaluated by using the continuous fit option on the distribution analysis subplatform. A posterior goodness of fit test was used to assess normality. Since data values for most parameters are shown not to be normally distributed, nonparametric statistical analyses were performed in all cases.

For treatment and/or parameter comparison across forest subtypes using a continuous variable as a response, the Kruskal-Wallis test was used by using the ranked-based testing option in the analysis platform of the program used. For comparison of means using a numerical variable between two treatments, the Wilcoxon test was used in a similar manner to the last approach. For correlation analysis between two continuous variables, Spearman's Rho nonparametric coefficient was used by using the nonparametric option in the multivariate platform. For all analyses, the alpha value used was 0.05 .

\section{Results and Discussion}

A total of 568 trees were studied in the eight study plots. Tree density was estimated in 490, 275, 1250, and 825 trees per hectare for the H1, H2, G1, and G2 forest types, respectively. It is interesting to note that dry forest subtypes had the lowest density values and that the Cupressus lusitanica dominated subtype had the highest one. This is a referent to the difficulty of establishing reforestation projects in tropical dry areas (see [12]) and to the high value of cypress for timber production purposes [13] due to its rapid growth. However, it also shows the relative effectivity of the Samanea saman-Hymenaea courbaril (H1) system to sustain a forest ecosystem.

Differences were found in canopy height among all study forest types $(H[3,661]=192.7, P<0.0001$; individual comparisons $P<0.0001$ in all cases). In the case of $\mathrm{DBH}$, differences were found between $\mathrm{Gl}$ and the other forest types $(H[3,567]=114.9, P<0.0001$; comparison G1 and others $P<0.0001)$. A similar pattern to the latter was also found for tree volume $(H[3,567]=143.96, P<0.0001$; comparison G1 and others $P<0.0001)$. Interestingly, the G1 forest type was the area that showed the highest values for canopy height, $\mathrm{DBH}$ and tree volume, whereas the lowest values were recorded in the $\mathrm{H} 2$ type (Table 1 ).

As mentioned before, the latter values can be seen as an indicator of the success of the cypress subforest in terms of biomass accumulation. However, it is interesting to analyze the results in the context of the other subforests studied. Nonnative forest patches have lost popularity in Costa Rica [14] as well as in other places due to the changes in ecosystem dynamics produced by a rapid introduction of selective forces associated to the introduction of species.

When forest parameters were analyzed, neither the total above ground biomass nor the average ground biomass showed any significant differences among forest subtypes. Above ground carbon, $\mathrm{CO}_{2}$-equivalent sequestered units and below ground biomass showed a similar pattern with no differences among forest subtypes when average values were studied (see Table 2). Results show that at this level, the studied forest subtypes seem equivalent. 
TABLE 1: Basic parameter values and standard deviations of the forest subtype characterization performed in the present study.

\begin{tabular}{lcccccc}
\hline Plot & DBH $(\mathrm{cm})$ & $\mathrm{CH}(\mathrm{m})$ & $\mathrm{TV}\left(\mathrm{m}^{3}\right)$ & $\mathrm{MT}\left({ }^{\circ} \mathrm{C}\right)$ & MAM $(\%)$ & MI $(\mathrm{Lux})$ \\
\hline H1 & $20.7 \pm 1.9$ & $7.1 \pm 0.2$ & $0.56 \pm 0.07$ & $26.6 \pm 4.1$ & $75.3 \pm 18.6$ & $606.1 \pm 1536.8$ \\
H2 & $20.2 \pm 1.3$ & $5.6 \pm 0.3$ & $0.34 \pm 0.09$ & $26.8 \pm 4.5$ & $72.0 \pm 18.0$ & $770.1 \pm 1438.7$ \\
G1 & $29.1 \pm 0.6$ & $11.9 \pm 0.2$ & $0.98 \pm 0.04$ & $16.6 \pm 1.7$ & $88.8 \pm 12.7$ & $128.4 \pm 398.4$ \\
G2 & $21.9 \pm 0.7$ & $9.2 \pm 0.2$ & $0.63 \pm 0.05$ & $16.6 \pm 1.9$ & $68.2 \pm 27.2$ & $314.3 \pm 1259.5$ \\
\hline
\end{tabular}

Abbreviations correspond to diameter at breast height (DBH), canopy height $(\mathrm{CH})$, total tree volume (TV), mean temperature (MT), mean atmospheric moisture (MAM), and mean illuminance (MI).

TABLE 2: Tree-based estimator average values and standard deviations calculated for the forest subtypes in the present study. All values are given in megagrams per hectare.

\begin{tabular}{lcccc}
\hline Plot & AGB & AGC & $\mathrm{CO}_{2}$-EU & BGB \\
\hline H1 & $154.4 \pm 13.1$ & $76.6 \pm 6.4$ & $277.4 \pm 27.5$ & $43.2 \pm 3.6$ \\
H2 & $76.4 \pm 36.3$ & $35.9 \pm 17.7$ & $131.8 \pm 65.2$ & $20.5 \pm 10.1$ \\
G1 & $470.1 \pm 2.8$ & $230.3 \pm 1.4$ & $844.5 \pm 5.1$ & $90.0 \pm 0.5$ \\
G2 & $243.9 \pm 63.4$ & $119.5 \pm 31.0$ & $438.3 \pm 80.5$ & $58.5 \pm 15.2$ \\
\hline
\end{tabular}

Abbreviations correspond to average ground biomass (AGB), average ground carbon (AGC), carbon dioxide equivalent units $\left(\mathrm{CO}_{2}\right.$-EU), and average below ground biomass (BGB).

Similarly, neither of the microclimatic parameters measured showed differences between forest subtypes $(H[3,7]=$ $5.5, P=0.13$ for temperature; $H[3,7]=3.6, P=0.29$ for atmospheric moisture; and $H[3,7]=5.1, P=0.16$ for illuminance). However, temperature showed some homogeneity within forest types, whereas both atmospheric moisture and light intensity showed a higher degree of variability (Table 1). Such result is easily understandable performing a combined macro- and microclimatic analysis. However, what is important in this case is the actual quantification of parameters and the implications for forest dynamics and integrated performance along with a different taxonomic group such as the fungi.

In that second part of the study, the most commonly recorded fungal genera overall were Collybia and Marasmius (see Table 3). However, for the G2 forest subtype, the genera Laccaria and Lactarius were the dominant forms. The four genera are among the most commonly recorded fungi in tropical areas. However, in spite of natural history differences among genera, the number of fungal fruiting bodies recorded was not significantly different across the different forest subtypes $(H[3,7]=6.0, P=0.16)$. Interestingly, for $\mathrm{G} 2$ about $47 \%$ of the records were mycorrhizal, whereas for $\mathrm{H} 1$ all of the genera present were saprophytes, but this apparent differences in guild composition were marginally not seen when the analysis across forest subtypes was performed $(H[3,7]=6.8, P=0.07)$.

Such an analysis is an important aspect to consider because the enzymatic battery among guilds is not equivalent [15] and biochemical differences have the potential of modifying the level in which wood decay, nutrient recycling, and soil biodiversity interact with trees. The latter observation may be the driver of the fact that fungi present in the G2 forest subtype, mostly mycorrhizal, were the heaviest ones. However, an analysis of total dry weights per forest subtype did not show any significant differences $(H[3,7]=4.6, P=$ $0.19)$.

The morphological parameters measured or calculated for fruiting bodies showed strong correlations among themselves (Table 4) but hymenial surface was the variable present in the majority of significant correlations. In this sense, the total hymenial surface was inversely and strongly correlated with atmospheric moisture $(\rho=-0.81)$ and hymenial surface was significantly larger in mycorrhizal than in saprophytic fungi $(Z=9.44, P=0.0001)$. Both results relate to fungal physiology but it is interesting that at higher levels of atmospheric moisture, fruiting bodies within a forest subtype showed a lower cumulative value of hymenial surface. This observation should be further evaluated due to the implication for forest dynamics. In fact, the case of mycorrhizal fungi should be of particular interest, due to the very particular cost-benefit balance with tree partners [16].

Finally, the reproductive success ratio showed a moderate negative correlation with the average biomass present in the forest subtypes studied $(\rho=-0.45)$ as well as with $\mathrm{DBH}$ values $(\rho=-0.30)$. This result seems to indicate that functional strategies and resource allocation in fungal fruiting bodies may partially depend on forest characteristics. For instance, it may not be surprising that in our study mycorrhizal fungi, which were present in areas with higher tree biomass values, showed significantly lower reproductive success ratios $\left(Z=-18.45, P=0.0001 ; 3.34 \mathrm{~mm}^{2} / \mathrm{g}\right.$ for mycorrhizal versus $8.26 \mathrm{~mm}^{2} / \mathrm{g}$ for saprophytic fungi).

Mycorrhizal fungi have a constant influx of carbon from trees and thus can allocate more resources in the production of biomass than their saprophytic counterparts. In our study, the average biomass of fruiting bodies was significantly higher for mycorrhizal fungi than for saprophytic ones $(Z=$ $18.76, P=0.0001 ; 0.28 \mathrm{~g}$ for saprophytes versus 1.89 for mycorrhizal fungi), providing another measurement of forest 
TABLE 3: Relative percentages of fruiting body incidence by forest subtype and average values for parameters measured across some of the fungal genera observed in the present study.

\begin{tabular}{|c|c|c|c|c|c|c|c|c|c|}
\hline \multirow{2}{*}{ Genus (fungi) } & \multicolumn{4}{|c|}{ Forest subtype } & \multicolumn{5}{|c|}{ Parameters measured } \\
\hline & G1 & G2 & $\mathrm{H} 1$ & $\mathrm{H} 2$ & DW & $\mathrm{PD}$ & $\mathrm{SD}$ & HS & RSR \\
\hline Amanita & & 0.8 & & & 5.5 & 3.9 & 0.6 & 13.8 & 2.9 \\
\hline Boletus & & 4.7 & & & & 2.9 & 0.6 & 8.5 & 2.4 \\
\hline Clitocybe & 5.8 & 6.7 & 0.7 & 13.5 & 3.0 & 3.4 & 0.6 & 9.6 & 2.8 \\
\hline Collybia & 16.8 & 6.2 & 79.7 & 16.4 & 0.5 & 2.0 & 0.2 & 3.9 & 9.5 \\
\hline Coltricia & & 2.5 & & & 1.1 & 3.0 & 0.4 & 8.6 & 10.1 \\
\hline Coprinus & & & 2.6 & 9.6 & 0.3 & 2.1 & 0.2 & 3.9 & 13.0 \\
\hline Coriolopsis & & & 0.3 & 3.7 & 2.2 & 2.8 & $\mathrm{n} / \mathrm{a}$ & 7.4 & 3.9 \\
\hline Cortinarius & & 3.6 & & & 4.3 & 2.8 & 1.0 & 6.0 & 3.2 \\
\hline Daedalea & & & 0.9 & 0.2 & 2.6 & 3.0 & $\mathrm{n} / \mathrm{a}$ & 3.3 & 1.9 \\
\hline Entoloma & 0.6 & 0.3 & & & 0.7 & 2.4 & 1.0 & 2.9 & 4.2 \\
\hline Fistulina & & & & 5.9 & 27.2 & 5.1 & 1.1 & & 1.2 \\
\hline Hexagonia & 2.9 & & & & & 6.8 & $\mathrm{n} / \mathrm{a}$ & & 13.4 \\
\hline Hydnum & & 2.0 & & & & 3.4 & 0.8 & & 2.3 \\
\hline Hygrocybe & 4.5 & 1.1 & & & 6 & 1.6 & 0.5 & 2.3 & 4.7 \\
\hline Inocybe & 6.9 & & & & 0.3 & 1.0 & 0.1 & 1.0 & 4.5 \\
\hline Laccaria & 2.9 & 16.7 & & & & 1.9 & 0.3 & 3.9 & 5.4 \\
\hline Lactarius & 1.2 & 15.3 & & 0.2 & 18.7 & 5.8 & .2 & 30.8 & 2.1 \\
\hline Leccit & & 0.4 & & & & & & & 0.4 \\
\hline Lentinula & & 0.3 & & & & & & & 6.1 \\
\hline Lentinus & & 1.1 & 0.2 & & & 6 & & & 7.7 \\
\hline Lenzites & & & 1.3 & 0.5 & 9 & 5.1 & $/ \mathrm{a}$ & 8.9 & 2.7 \\
\hline Lepiota & 0.6 & 0.4 & 1.8 & 2.7 & & 2.4 & 0.3 & 5.8 & 6.9 \\
\hline Leucoaga & 1.2 & 1.7 & 1.6 & 3.2 & & 1.8 & 0.3 & .1 & 4.5 \\
\hline Leucocopr & & & & 1.2 & 2 & 1.0 & 0.1 & 3 & 4.9 \\
\hline & & & & & & & 1.1 & & 3.1 \\
\hline & 2.0 & 3.6 & 8.5 & 15.4 & & & & & 9.8 \\
\hline Merulius & & 0.1 & & & 0.5 & 2.6 & 0.2 & & 1.1 \\
\hline Mycena & 1.4 & 0.7 & & 1.0 & 0.2 & 1.1 & 0.1 & & 9.4 \\
\hline Oudemans & & 1.3 & 0.9 & 0.2 & & 3.4 & 0.3 & 10.9 & 6.1 \\
\hline Panellus & & & & 0.2 & 2.8 & 6.5 & 0.5 & 3.0 & 1.1 \\
\hline Paneolus & & 0.1 & & 2.3 & 0.6 & 1.6 & 0.2 & 1 & 4.0 \\
\hline Panus & 2.9 & 5.5 & & & & 2.1 & 0.5 & & 15.0 \\
\hline & & 1.3 & 0.4 & & & 3.0 & 3.4 & & 10.8 \\
\hline Pholiota & 0.6 & 1.5 & & 0.2 & & 1.9 & 0.3 & & 5.1 \\
\hline & & & 0.3 & & & & & & 0.8 \\
\hline Pleurotus & 2.3 & & 0.9 & 4.7 & & 2.2 & 0.3 & & 12.2 \\
\hline Pluteus & 4.6 & 1.5 & & 5.1 & 2.8 & 3.5 & 0.6 & 14.4 & 4.1 \\
\hline Polyporus & & 0.7 & 1.4 & 8.9 & & 1.5 & 0.3 & & 2.0 \\
\hline Psatyrella & & 0.1 & & 0.2 & & 1.3 & 0.1 & 1.4 & 9.5 \\
\hline Psilocybe & & & & 0.2 & 7.3 & 4.0 & 0.7 & 12.2 & 1.7 \\
\hline Russula & & 3.2 & & & 8.0 & 4.4 & 1.0 & 16.6 & 2.8 \\
\hline & & & 1.1 & & & 2.9 & 0.4 & & 2.6 \\
\hline & 1.2 & 4.6 & & & & 2.3 & 0.7 & 4.8 & 1.5 \\
\hline Stereum & & 1.8 & & & 0.6 & 2.2 & $\mathrm{n} / \mathrm{a}$ & 6.0 & 14.3 \\
\hline Trametes & 15.7 & 1.5 & 0.3 & 0.7 & 3.0 & 3.6 & $\mathrm{n} / \mathrm{a}$ & 13.3 & 5.4 \\
\hline & 8.7 & 0.1 & & 3.9 & 4.5 & 4.3 & 0.6 & & 4.9 \\
\hline Tylopilus & & 0.4 & & & 174.2 & 12.4 & 1.8 & 121.3 & 0.7 \\
\hline
\end{tabular}

Abbreviations correspond to dry weight (DW), pileus diameter (PD), stalk diameter (SD), hymenial surface (HS), and reproductive success ratio (RSR).
TABLE 4: Spearman's Rho $(\rho)$ correlation values for all four variables calculated after the fungal fruiting bodies were studied in the present study.

\begin{tabular}{lcccc}
\hline & DW & PD & SD & HS \\
\hline DW & 1.00 & 0.83 & 0.76 & 0.79 \\
PD & & 1.00 & 0.64 & 0.92 \\
SD & & & 1.00 & 0.61 \\
HS & & & & 1.00 \\
\hline
\end{tabular}

Abbreviations correspond to average dry weight (DW), pileus diameter (PD), stalk diameter (SD), and hymenial surface (HS).

dynamics assessment. For the forest subtypes studied in the present investigation, such values represent a valuable quantification of parameters for the understanding of the role of fungi in tropical forest dynamics.

A more thorough examination of certain aspects documented in the present study is necessary in order to understand in more detail the dynamics and functional relationships between trees and fungal inhabitants of forest ecosystems. In spite of the latter, due to the early stage of integrated tree-fungus ecological analyses in Costa Rica, we consider the present effort a locally based contribution in the right direction.

\section{Conclusion}

It is difficult to understand tropical forest dynamics by analyzing only tree data. As an effort to integrate forest performance values and microbial dynamics, basidiomycete fungi were selected in the present study. Results from four different forest subtypes belonging to two different life zones in Costa Rica showed that even though tree biomass accumulation may be higher in forest patches dominated by introduced species, a parallel biodiversity-based assessment can be useful to understand the dynamics within the forest.

For tropical areas of the world, where integrated forest studies are less common than monothematic ones, this type of investigation is valuable to accumulate data on forest interactions with both external and internal evolutionary forces and monitor their performance over time.

\section{Conflict of Interests}

The authors declare that there is no conflict of interests regarding the publication of this paper.

\section{Acknowledgments}

This study has been funded by University of Costa Rica through Vicerrectoría de Investigación research code 731-B2222. Gratitude is expressed to the personnel of the Reserva Forestal Grecia and the Estación Experimental Forestal Horizontes for granting permission to work in those areas. Appreciation is also extended to Irene Calderón, Stephanie Somerville, and Randall Valverde for field support and to 
the Engineering Research Institute at University of Costa Rica for logistic help. Finally, appreciation is extended to anonymous reviewers that constructively increased the quality of a previous version of the paper.

\section{References}

[1] M. S. Nicholson, "Some spiritualistic uses of mushrooms," Fungi, vol. 2, no. 2, pp. 26-27, 2009.

[2] M. S. Strickland and J. Rousk, "Considering fungal: bacterial dominance in soils-methods, controls, and ecosystem implications," Soil Biology and Biochemistry, vol. 42, no. 9, pp. 13851395, 2010.

[3] D. Johnson, F. Martin, J. W. G. Cairney, and I. C. Anderson, “The importance of individuals: intraspecific diversity of mycorrhizal plants and fungi in ecosystems," New Phytologist, vol. 194, no. 3, pp. 614-628, 2012.

[4] M. C. Brundrett and N. Ashwath, "Glomeromycotan mycorrhizal fungi from tropical Australia III. Measuring diversity in natural and disturbed habitats," Plant and Soil, vol. 370, no. 1-2, pp. 419-433, 2013.

[5] P. Dion, Ed., Soil Biology and Agriculture in the Tropics, Springer, Berlin, Germany, 2010.

[6] V. Obando, Biodiversidad de Costa Rica en Cifras, INBio, Santo Domingo de Heredia, Costa Rica, 2007.

[7] S. W. Chou and E. Gutiérrez-Espeleta, "Ecuación para estimar la biomasa arbórea en los bosques tropicales de Costa Rica," Tecnología en Marcha, vol. 26, no. 2, pp. 41-54, 2012.

[8] IPCC, Guidelines for National Greenhouse Gas Inventories, ICES, Hayama, Japan, 2006.

[9] S. P. Singh, B. S. Adhikari, and D. B. Zobel, "Biomass, productivity, leaf longevity, and forest structure in the central Himalaya," Ecological Monographs, vol. 64, no. 4, pp. 401-421, 1994.

[10] K. Mokany, R. J. Raison, and A. S. Prokushkin, "Critical analysis of root: shoot ratios in terrestrial biomes," Global Change Biology, vol. 12, no. 1, pp. 84-96, 2006.

[11] J. D. Pallua, W. Recheis, R. Pöder et al., "Morphological and tissue characterization of the medicinal fungus Hericium coralloides by a structural and molecular imaging platform," Analyst, vol. 137, no. 7, pp. 1584-1595, 2012.

[12] M. Worbes, S. Blanchart, and E. Fichtler, "Relations between water balance, wood traits and phenological behavior of tree species from a tropical dry forest in Costa Rica-a multifactorial study," Tree Physiology, vol. 33, no. 5, pp. 527-536, 2013.

[13] N. G. Mehta and W. A. Leuschner, "Financial and economic analyses of agroforestry systems and a commercial timber plantation in the La Amistad biosphere reserve, Costa Rica," Agroforestry Systems, vol. 37, no. 2, pp. 175-185, 1997.

[14] J. S. Hall, M. S. Ashton, E. J. Garen, and S. Jose, “The ecology and ecosystem services of native trees: implications for reforestation and land restoration in Mesoamerica," Forest Ecology and Management, vol. 261, no. 10, pp. 1553-1557, 2011.

[15] P. Baldrian, "Ectomycorrhizal fungi and their enzymes in soils: is there enough evidence for their role as facultative soil saprotrophs?" Oecologia, vol. 161, no. 4, pp. 657-660, 2009.

[16] K. H. Orwin, M. U. F. Kirschbaum, M. G. St John, and I. A. Dickie, "Organic nutrient uptake by mycorrhizal fungi enhances ecosystem carbon storage: a model-based assessment," Ecology Letters, vol. 14, no. 5, pp. 493-502, 2011. 

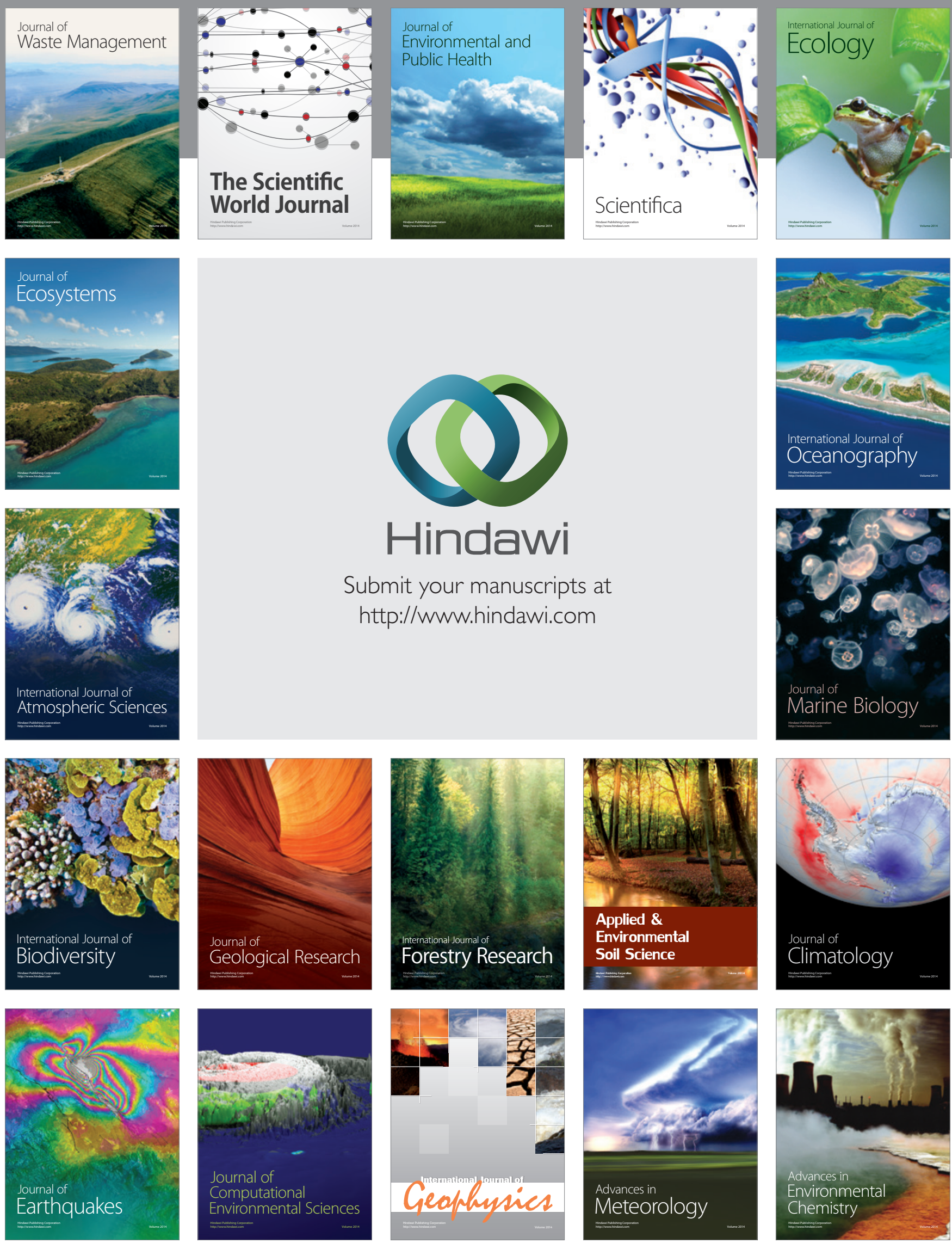